\title{
Traffic Crimes and risky driving: The role of personality and driving anger
}

\author{
José María Faílde-Garrido ${ }^{1,2}\left({ }^{-} \cdot\right.$ Yolanda Rodríguez-Castro $^{1} \cdot$ Antonio González-Fernández $^{1}$. \\ Manuel Antonio García-Rodríguez ${ }^{3}$
}

Accepted: 13 December 2021

(c) The Author(s) 2021

\begin{abstract}
The current study aims to examine the influence of personality traits (alternative Zuckerman model) and driving anger in the explanation of risky driving style in individuals convicted for road safety offences $(\mathrm{N}=245)$, using as a basis an adaptation of the context-mediated model. This is a transversal, descriptive study designed to be implemented by means of surveys, in which took part 245 men convicted of road safety offences from five prisons in Galicia (a region in northwestern Spain) took part. The average age of the participants was 38.73 years (Sx-9.61), with a range between 18 and 64 years. All participants had three or more years of driving experience. Our data shows that the Impulsive-Sensation Seeking (Imp-SS) personality trait had a direct and positive effect on dangerous driving, while the Activity (Act) trait had a direct but negative effect. The Aggression-Hostility (Agg-Host) trait, in turn, influenced the risky driving style, but not directly, but by raising driving anger levels, so it acted as a powerful mediator between the Aggression-Hostility (Agg-Hos) trait and the risky driving style. In general, our research partially replicates and expands previous findings regarding the model used, the aggression-hostility personality trait (Agg-Host) was placed in the distal context, driving anger in the proximal context, while age and personality traits Activity (Act) and Impulsive-Sensation Seeking (Imp-SS) were direct predictors. The results of this study may have practical implications for the detection and rehabilitation of offenders and penalties for road safety offences.
\end{abstract}

Keywords Personality traits $\cdot$ Driving anger $\cdot$ Risky driving style $\cdot$ Convicts $\cdot$ Road safety

\section{Introduction}

There are multiple variables that influence a traffic accident (Vlahogianni et al., 2012), but can be synthesized into the complex network of interactions between track characteristics, vehicle, environmental circumstances, and driver

José María Faílde-Garrido

jfailde@uvigo.es

Yolanda Rodríguez-Castro

yrcastro@uvigo.es

Antonio González-Fernández

aglez@uvigo.es

Manuel Antonio García-Rodríguez

manuelcenlle@hotmail.com

1 University of Vigo, Ourense 32004, Spain

2 University of Vigo, Faculty of Education and Social Work, Ada./ Castelao S/N, Ourense, Spain

3 Pereiro de Aguiar Penitentiary Center, Ourense, Spain behavior (Mohan et al., 2006). Among all these variables, the human factor is the one that explains to a greater extent the causality of traffic accidents (Singh, 2015). Likewise, certain driver behaviours such as errors and violations explain most accidents (Reason et al., 1990). Behaviours that are closely related to risky, aggressive, and other maladaptive driving styles (Gulliver \& Begg, 2007; Paleti et al., 2010).

Road crime is one of the most prevalent types of crime today, however, it has been much less studied than other types of criminal offenses (Castillo-Manzano et al., 2015). In Spain, as in many other countries, the legislative changes that have occurred in recent years have caused certain driving offences that were previously constitutive of an administrative sanction, to now be classified as delelective acts. As a result, there are many people who enter prison without having a previous criminal history for other types of crimes, ignoring the clinical and sociodemographic profile of these criminals (Faílde et al., 2018; Fiscalía General del Estado, 2019; Hilterman et al., 2012). Thus, the issue becomes 
necessary to increase knowledge about it and put it at the service of those in charge of designing and implementing rehabilitative measures (Fiscalía General del Estado, 2017; Monras et al., 2011).

The current study aims to examine the influence of personality traits (alternative Zuckerman model; Zuckerman et al., 1993) and driving anger in explaning the risky driving style, in individuals convicted for road safety offences, using as a basis an adaptation of the context-mediated model.

\section{Literature Review}

\section{Risky Driving}

The behavior of the driver can be defined as the driving style intentionally chosen by the individual and that is influenced by their personality characteristics, their attitudes, or motivations (Demir et al., 2016).

Risky driving is one that creates a risk or danger by the way of driving, and which can affect the drivers temselves, the other occupants of the vehicle and/or other road users, constituting a serious danger to road safety (Charlton, 2009; McNally \& Bradley, 2014).

The main types of risky driving behind the wheel may include driving with clearly excessive speed (Hatfield \& Fernandes, 2009; Simons-Morton et al., 2005); making dangerous overtaking, circulating excessively close to the vehicle that precedes us (Harris \& Houston, 2010), using mobile or other electronic devices to speak or text (Owens et al., 2011), or driving under the influence of alcohol or drugs (Calafat \& Duch, 2009). Overall, scientific evidence indicates that this type or behaviors, are much more frequent, but not exclusive, of young drivers (McEvoy et al., 2007; McNally \& Bradley, 2014); being, in turn, more prevalent in males than in women (McNally \& Bradley, 2014).

However, to accurately assess risky driving behaviour, it is necessary to distinguish between errors and violations (Reason et al., 1990). The first are involuntary acts, while the latter are mostly deliberate actions (Precht et al., 2017).

There are several indicators for assessing the risky driving style among which we can highlight direct indicators, such as the number of accidents or traffic violations, but also questionnaire measures that include specific scales to assess risky driving, such as the Dangerous Driving Index (Dula \& Geller, 2003), the Driving Behaviour Questionnaire (Lawton et al., 1997; Reason et al., 1990), or the Multidimensional Driving Style Inventory (Taubman-Ben-Arib $\&$ Skvirsky, 2016). The latter instrument has been adapted and tested in different countries, showing good metric qualities which allows us to determine different driving styles (Long \& Ruosong, 2019; Taubman-Ben-Arib \& Skvirsky, 2016). The risky driving style refers "to an active search for emotions and sensations linked to risk in driving, which are associated with behaviors such as driving at high speed, driving to the limit, violating traffic rules, etc. " (Poó et al., 2008, p.270).

There are multiple predictors of risky driving, among which personality traits (Javid et al., 2021; Lucidi et al., 2019; Taubman-Ben-Arib \& Yehiel, 2012) and driving anger (McNally \& Bradley, 2014; Richer \& Bergeron, 2012), can be mentioned.

\section{Personality Traits and Risky Driving Style}

Several studies indicate that a minority percentage of drivers tend to accumulate the highest number of accidents and road infringements (Sánchez \& Quiroga, 2005; Shaw \& Sichel, 1971). This fact led to the development of classical theoretical formulations that emerged under the approach to individual differences such as the theory of accident proneness that assumed that some people have an inherent tendency to get involved in accidents (Shaw \& Sichel, 1971) or subsequent approaches such as differential accident involvement (McKenna, 1983); which has led many researchers to try to establish relationships between driving styles and road offender personality traits (Taubman-Ben-Arib \& Yehiel, 2012; Wang et al., 2018).

Personality traits define, with a certain degree of consistency and stability, people's characteristic patterns of thoughts, feelings, and behaviours. Among the most commonly used instruments for evaluation in the context of risk driving study is the Revised NEO Personality Inventory (Costa \& McCrae, 1992), the Big Five Questionnaire (Caprara et al., 1993), or the Zuckerman-Kuhlman Personality Questionnaires Cross Cultural, which evaluates five dimensions of the alternative personality model (Zuckerman et al., 1993). The latter instrument has the advantage of integrating various personality dimensions into a unified theoretical model, which have been associated with risky driving, such as the Aggression-Hostility or the Impulsive-Sensation Seeking (Poó et al., 2008).

On the contrary, other traits such as kindness, awareness, and openness to change relate to styles of prudent driving (Harris et al., 2014). While early studies did not shed much light on the role of personality traits in explaining behaviours that pose a risk to road safety (Sümer, 2003), new methodological approaches and theoretical models have begun to emerge in recent decades to better study the relationship of personality traits to driver behaviour or with outcome variables such as traffic accidents or fines (Burtăverde et al., 2016; Hasaninasab et al., 2021; Lajunen, 1997; Sümer, 2003). Some theoretical models point out that certain drivers' personality traits can influence risky driving behaviours, either directly, or indirectly through attitudes dealing with road safety (Javid \& Al-Hashimi, 2020; 
Ulleberg \& Rundmo, 2003). Other theoretical developments, such as the contextual model of Sümer (2003), distinguish between distal and upcoming factors in the explanation of traffic accidents, located to personality characteristics in the distal context and driving styles in a proximal context. The risky driving style has been positively associated with traits such as aggression and Aggression-Hostility (Bogdan et al., 2016; Lajunen \& Parker, 2001; Yang et al., 2013), the Impulsive and Sensation-Seeking (Begg \& Angley, 2004; Delhomme et al., 2012; Marengo et al., 2012; Poó \& Ledesma, 2013; Richer \& Bergeron, 2012), or neuroticism (Jovanović et al., 2011). On the other hand, the risky driving style has also been associated with the so-called Dark Personality Triad-machiavelism, psychopathy and narcissism-(Paulhus \& Williams, 2002), these traits have also been linked to risky behaviors, such as drug use or aggressive driving (Burtăverde et al., 2016). On the contrary, other traits such as kindness, awareness and openness to change relate to styles of prudent driving (Harris et al., 2014).

\section{Relationship of Driving Anger with Risky Driving Style}

As Nesbit and Conger (2011) point out driving anger is considered a situation-specific emotional construct, composed of feelings and thoughts related to this emotion that take place while driving. The triggering of anger, while driving, appears to be affected by multiple factors, including the nature of anger and situational factors (Lajunen \& Parker, 2001; Zhang \& Chan, 2016).

Scientific evidence indicates that driving anger is one of the most important factors in explaining risky or insecure driving (Dingus et al., 2016; Lucidi et al., 2019; Richer \& Bergeron, 2012), while it does not seem clear what the relationship between dangerous driving and anger is. In this sense, a recent study made by Precht et al. (2017) indicates that anger causes situations of danger, not so much because it interferes with cognitive functioning, but because of the deliberate risk behaviors that the driver performs under this emotional state. In addition, these authors, point out that deliberate violations appear to be related to anger triggering in reaction to a threat, provocation or frustration. Other studies point out that driving anger is more related to deliberate violations (such as aggressive behaviors directed at other road users) rather than to errors or omissions in driving (Berdoulat et al., 2013; Zhang \& Chan, 2016). While the effect that anger may have on driving errors or omissions (Jeon et al., 2014) cannot be ruled out; Zhang \& Chan, 2016).

Although there are not many studies, there is scientific evidence linking driving anger to the risky driving style (Deffenbacher et al., 2016; Kovácsová et al., 2014; Padilla et al., 2020; Precht et al., 2017; Sullman et al., 2015; Zhang \& Qu, 2018)

For the assessment of anger while driving, one of the most widely used instruments is the Driving Anger Scale (DAS; Deffenbacher et al., 1994), which has been adapted to multiple contexts (Sârbescu, 2016).

\section{Relationship between Driving Anger and Personality Traits}

Several investigations have established relationships between driving anger and other personality traits (Deffenbacher, et al., 2016). A meta-analytical study conducted by Demir et al. (2016) found low, although significant, correlations with all the personality dimensions of the Big Five model, except for the neuroticism trait. However, this same study found more intense associations with some personality groups dependent on these dimensions, as was the case with the facet of seeking sensations, normlessness, or narcissism.

For their part, Jovanović et al. (2011) found that neuroticism had a positive association with anger while driving, while kindness had a negative indirect effect on it. Likewise, a recent study, conducted by Karimi et al. (2021) found that the neuroticism trait (Big Five Model) was related to all forms of anger expression evaluated by the Driving Anger Expression Inventory (DAX).

Other studies have found a relationship between driving anger and the type A behavior pattern and with the anger trait (Feng et al., 2017), narcissism (Edwards et al., 2013) or with sensation seeking and impulsivity (Stephens and Sullman, 2015).

But without any doubt, the personality dimension that has shown the most intense positive associations with anger is aggression (Demir et al., 2016; Mirón-Juárez et al., 2020; Poó et al., 2008; Sullman et al., 2007).

\section{Theoretical Model}

Various theoretical models have been proposed to try to explain the role of personality traits and driving anger on the driver's behavior or on outcome variables such as traffic accidents or fines. These models include the Mediation Logic Model (Baron \& Kenny, 1986), the Horizontal Model (Lajunen, 1997) or the Contextual Mediated Model (Elander et al., 1993; Sümer, 2003). In this study we will take as a reference the proposal of Demir et al. (2016), that synthesizes these three models placing personality factors and sociodemographic characteristics in the distal context -in our case the five personality dimensions of the alternative model of Zuckerman et al. (1993) and age-, in the proximal context driving anger (DAS) is placed and as a behaviuoral outcome the driving style (in our model the risky driving 
style). A representation of the model can be seen in Fig. 1. In the upper part, of the former figure, you can see the original proposal of the model raised by Demir et al. (2016). In the lower part you can see the predictor variables (Dixtal Contex), the mediating variable (Proximal Contex) and the result variable (Behavioral outcomes), which have been tested in this study. In the light of this, we hypothesize that:

H1. Personality traits and age correlated with risky driving style indirectly through driving anger.

$\mathrm{H} 2$. The direct correlations between personality traits and age with risky driving will be less intense or absent.

\section{Materials and Methods}

\section{Participants}

In this study 245 men convicted of road safety offences from five prisons in Galicia (a region in northwestern Spain) took part. The average age of the participants was 38.73 years (Sx-9.61), with a range between 18 and 64 years. All participants had three or more years of driving experience.

All of them had one or more offences against road safety as a main crime. A $47.75 \%$ had only a record for crimes against road safety, while the remaining $52.25 \%$ also had previous convictions for other types of criminal offenses. While the most frequent crime of conviction was "driving under the influence of alcohol or drugs" (60\%), the main reasons for imprisonment were driving without a driver's licence (in most cases because it was removed) and reckless homicide.

\section{Instruments}

Personality Dimensions For this purpose, the Spanish version of The Zuckerman-Kuhlman Personality Questionnaire Cross Cultural 50-items (ZKPQ-50-CC) was used. This instrument was developed to assess the personality dimensions that constitute the Alternative Five-Factor Model (Zuckerman, et al., 1993): Aggression-Hostility (hereinafter Agg-Host), Impulsive-Sensation Seeking (hereinafter ImpSS), Neuroticism-

Anxiety (hereinafter N-Anx), Sociability (hereinafter Sy) and Activation (hereinafter Act). Each dimension consists of 10 items, with a diatomical (true-false) response format. For a larger description see Aluja et al. (2006).

Driving Anger The short version of the Spanish-adapted Driving Anger Scale (DAS) consisting of 14 items, in a 5-point Likert response format, was used from1 (nothing) to 5 (much), from which three subscales are extracted: Impeded Progress, Reckless Driving, and Direct Hostility. For a further description, see (Herrero-Fernández, 2011).

Risky Driving Style It was evaluated using the Risky Driving Scale of the Multidimensional Driving Style Inventory, Spanish version (MDSI-S) was used. This scale consists of 9 items with a 6-point liker response format from 1 (nothing) to 6 (much). For a further description, see Poó et al. (2013).

In addition to these instruments, an ad hoc designed questionnaire was administered that collected information on basic socio-descriptive data and other drivingrelated data.
Fig. 1 Contextual Mediated Model adapted from Demir et al. (2016)

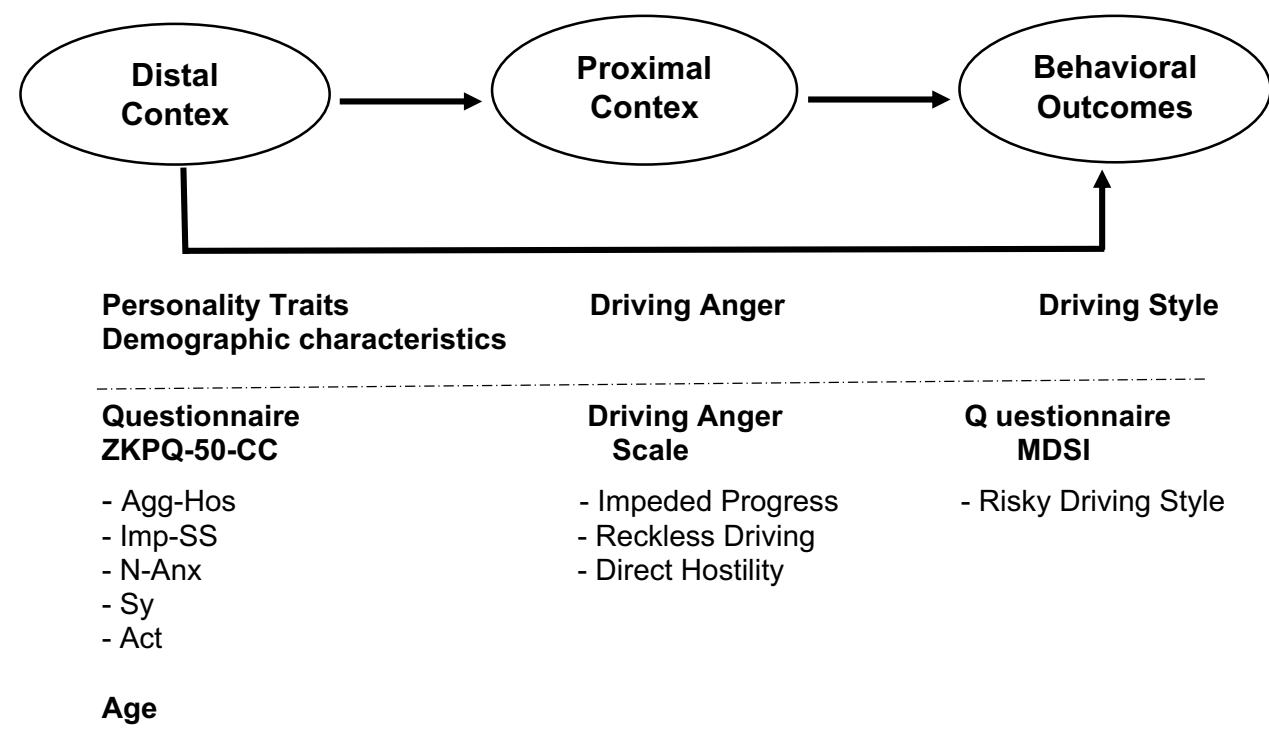




\section{Procedure}

To gain access to the population of inmates sentenced for crimes against road safety, the pertinent authorization was obtained from the Directorate General for Penitentiary Institutions, Government of Spain. The study was approved by the Ethics Committee of the Doctoral Program in Educational and Behavioral Sciences of the University of Vigo (CE-DCEC-UVIGO-2018-02-23-6462). This authorization guarantees that the study complies with the ethical principles included in the Declaration of Helsinki, for studies with human beings. Prior to their inclusion in the study, all participants were informed of the purpose of the research and their written informed consent was obtained. Their participation in the study was voluntary and their anonymity and the confidentiality of the reported data were always guaranteed. All the participants were evaluated individually and took an average of 40 to $50 \mathrm{~min}$ to complete the Evaluation instruments.

The data from this study are publicly available to download from the Inter-university Consortium for Political and Social Research (ICPSR): Access not available to mask the identity of the authors.

\section{Design}

This is a descriptive, cross-sectional study using surveys. The dependent variable was risky driving style, while the independent variables used were the personality traits of the alternative Zuckerman model, driving anger and the age of the participants.

\section{Statistical Analysis}

Data analysis was carried out in four phases. In the first, using the SPSS statistical package, reliability coefficients (Cronbach alpha) and correlations between variables were calculated, and a step-by-step regression analysis was performed to determine the predictors of risk driving style. Second, using the AMOS statistical package, the two necessary steps were performed in structural equation models (SEM), analyzing the measurement model and the structural model for the entire sample (Byrne, 2016). Third, a multigroup SEM model was carried out to compare younger drivers with older drivers ( $\leq 40$ years old $v s>40$ years old). Finally, the possible indirect effects on the model corresponding to the total sample were analyzed (Preacher \& Hayes, 2008).

The chi-square divided by the degrees of freedom $\left(\chi^{2} / d f\right)$, the comparative fit index (CFI), the normed fit index (NFI) and the root mean square error of approximation (RMSEA) were used as goodness-of-fit index (CFI) index index (NFI) and the root mean square error of approximation (RMSEA) models. For both CFI and NFI, values greater than 0.90 indicate adequate fit. For RMSEA, values below 0.08 indicate acceptable fit (Byrne, 2016).

\section{Results}

\section{Preliminary Analyses}

First, the reliability coefficients (Cronbach alphas) and the correlations between variables were calculated. The results are presented in Table 1.

For reliability indices, except for the sociability personality trait (Sy) who obtained a Cronbach's alpha of 0.399 , the others coefficient alpha can be considered satisfactory and consistent with those obtained in previous validations of the scales (see Table 1). Regarding the correlations, it is especially relevant to analyze the relationships between risky driving style and the other variables. In this sense, it is noted that risky driving style correlate positively with Agg-Host, Imp-SS and driving anger, and negatively correlate with age; correlations with other variables (Act, $N$-Anx, and $S y)$ were
Table 1 Correlations between variables and reliability indices

\begin{tabular}{lllllllll}
\hline & 1 & 2 & 3 & 4 & 5 & 6 & 7 & 8 \\
\hline 1. Age & - & & & & & & & \\
2. Act & -0.10 & - & & & & & & \\
3. Agg-Host & -0.15 & 0.10 & - & & & & & \\
4. Imp-SS & -0.13 & 0.20 & 0.48 & - & & & \\
5. N-Anx & 0.02 & 0.14 & 0.28 & 0.18 & - & & \\
6. Sy & -0.01 & 0.11 & 0.04 & 0.22 & -0.04 & - & \\
7. Driving anger & -0.14 & -0.06 & 0.37 & 0.18 & 0.11 & -0.08 & - & \\
8. Risky driving style & -0.38 & -0.10 & 0.39 & 0.39 & 0.12 & 0.06 & 0.36 & - \\
Cronbach's Alpha & - & .654 & .702 & .712 & .771 & .399 & .836 & .800 \\
\hline
\end{tabular}

$r<|0.14|$ : no significant; $r>|0.14|$ : significant at $p<.05 ; r>|0.17|$ : significant at $p<.01 ; \mathrm{r}>|0.27|$ : significant at $p<.001$ 
not significant. As for age, it only related significantly to Agg-Host, driving anger and with risky driving style.

A step-by-step regression analysis was then performed to determine the significant predictors of risk driving style. In the first step the age variable was introduced; in the second, the personality traits; and in the third, driving anger. The results are presented in Table 2.

Looking at Table 2, in the Step 1 we find that age is a negative predictor of risk driving style, explaining to $14.3 \%$ of his variance. In the Step 2, the inclusion of the Zuckerman's Alternative Five-factor explained variance an additional $20.2 \%$, with three significant predictors, one negative (Act) and the other two positive (Agg-Host and Imp-SS). In the step 3, driving anger was a positive or significant predictor of risk driving style, increasing by $3.4 \%$ of the variance explained. Comparing the results of regression with correlations (Table 1), Act is found to be a significant negative predictor of risk driving style, even though the correlation between the two variables was not significant.

In summary, analyzing Table 1 and Table 2 we find that $N-A n x$ and $S y$ do not correlate with (and do not predict) significantly risk driving style.

\section{SEM: Measurement and Structural Models}

We applied a two-step approach to confirm the proposed model of Fig. 1. The first step tested the measurement model through a CFA. In the present study, the number of applied items was 74 . To reduce the number of indicators per latent variable, following the suggestions of Byrne (2016), we parcelled the items of the subscales of Act, Agg-Host, Imp-SS and risky driving style, creating two parcels for each subscale; furthermore, the three subscales of driving anger were used as indicators. Thus, the measurement and the structural models included 5 latent variables, containing 11 indicators, and the manifest variable of Age (see Fig. 2).
All the indicators showed adequate skewness and kurtosis. The measurement model fit the data satisfactorily $\left[\chi^{2} / d f=1.36 ; \mathrm{CFI}=0.982 ; \mathrm{TLI}=0.972 ; \mathrm{RMSEA}=0.039\right.$, $\mathrm{CI}=0.000,0.062]$. The factor loadings (i.e., the correlations between indicators and latent variables) ranged from 0.57 to 0.95 and all were significant $(p<0.001)$.

Then, using SEM, we tested the hypothesized associations between the variables proposed in Fig. 1. The model fit the data properly $\left[\chi^{2} / d f=1.113 ; \mathrm{CFI}=0.995 ; \mathrm{TLI}=0.991\right.$; RMSEA $=0.022, \mathrm{CI}=0.000,0.050]$. Figure 3 shows the direct paths between measured variables.

Regarding direct significant relationships, driving anger was positively predicted by Agg-Host; on their hand, risky driving style was positively predicted by driving anger and Imp-SS, and was negatively predicted by Act and age. The percentages of explained variance were $27 \%$ for driving anger and $57 \%$ for risky driving style.

\section{Multigroup Comparison}

Since the age variable was a significant predictor of risky driving style, as found in the previous point, participants were divided into two age groups and a multigroup SEM was performed to check whether the model could be considered equivalent in different age groups. To this end, the sample was divided into two subsamples: the first was made up of participants 40 years of age or younger (49\%); the second subsample included participants over 41 years of age (51\%). The results of this comparison using multigroup SEM are presented in Fig. 4.

The joint model was appropriately adjusted to the data $\left[\chi^{2} / d f=1.009 ; \mathrm{CFI}=0.999 ; \mathrm{IFI}=0.999 ; \mathrm{NFI}=0.926\right.$; RMSEA $=0.06, \mathrm{CI}=0.000,0.039]$. The model of younger drivers was also fitted to the data $\left[\chi^{2} / d f=1.137 ; \mathrm{CFI}=0.989\right.$; $\mathrm{TLI}=0.981$; RMSEA $=0.034, \mathrm{CI}=0.000,0.039]$ and the model of older conductors was specially well adjusted $\left[\chi^{2} /\right.$

Table 2 Hierarchical linear regression analysis predicting risk driving style

\begin{tabular}{|c|c|c|c|c|c|c|}
\hline \multirow[b]{2}{*}{ Predictors } & \multicolumn{2}{|l|}{ Step 1} & \multicolumn{2}{|l|}{ Step 2} & \multicolumn{2}{|l|}{ Step 3} \\
\hline & $\beta$ & $t(p)$ & $\beta$ & $t(p)$ & $\beta$ & $t(p)$ \\
\hline Age & -0.378 & $-6.37 * * *$ & -0.333 & $-6.22 * * *$ & -0.314 & $-5.99 * * *$ \\
\hline Act & & & -0.217 & $-4.00 * * *$ & -0.197 & $-3.70 * * *$ \\
\hline Agg-Host & & & 0.224 & $3.63 * * *$ & 0.156 & $2.47 *$ \\
\hline Imp-SS & & & 0.265 & $4.26 * * *$ & 0.257 & $4.28 * * *$ \\
\hline N-Anx & & & 0.046 & 0.84 & 0.043 & 0.79 \\
\hline Sy & & & 0.018 & 0.32 & 0.036 & 0.67 \\
\hline Driving anger & & & & & 0.202 & $3.61 * * *$ \\
\hline$F\left(\mathrm{df}, \mathrm{df}_{\text {error }}\right)$ & $40.58(1,243)^{* * *}$ & & $20.89(6,238) * * *$ & & $20.67(7,237)^{* * *}$ & \\
\hline$R^{2}$ & $0.143 * * *$ & & $0.345^{* * *}$ & & $0.379 * * *$ & \\
\hline$\Delta R^{2}$ & & & $0.202 * * *$ & & $0.034 * * *$ & \\
\hline
\end{tabular}

${ }^{*} p<.05 ; * * p<.01 ; * * * p<.001$ 


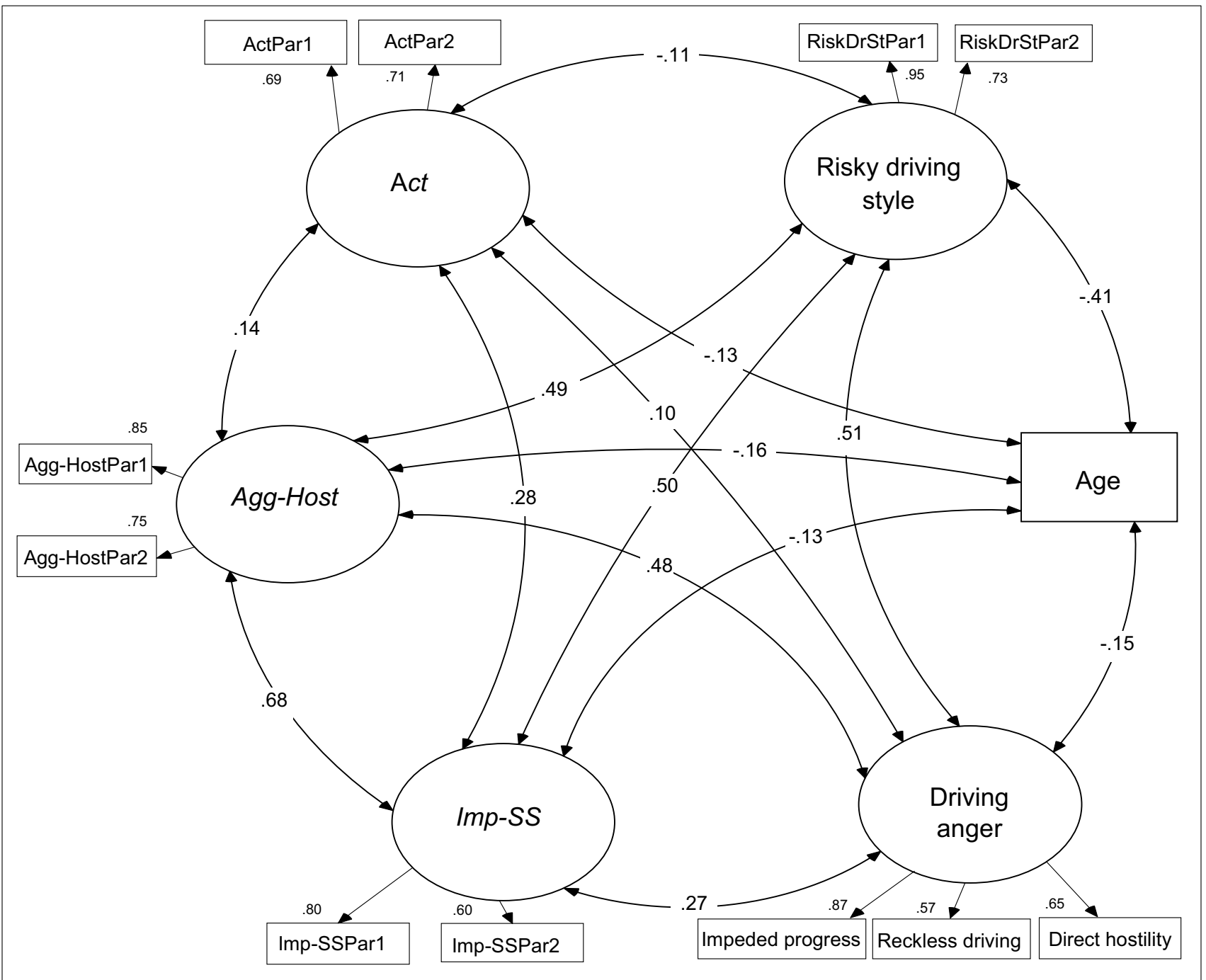

Fig. 2 Standardized covariances and factor loadings of the measurement model. Note. Covariances $\leq|0.14|$ are no significant ( $p>0.05$ ); covariances $\geq|0.15|$ are significant at $\mathrm{p}<.05$. All factor loadings were significant $(\mathrm{p}<0.001)$

$d f=0.882 ; \mathrm{CFI}=1.000 ; \mathrm{TLI}=1.000 ; \mathrm{RMSEA}=0.000$, $\mathrm{CI}=0.000,0.055]$. In the light of Fig. 4 we find that, in some regression weights, there are obvious differences between the two groups of drivers, the younger versus the older ones. This is the case with the values obtained in the path that joins $A c t$ with risky driving style ( $\beta-0.06$ versus $\beta-0.44$ ) and in the path that associates Imp-SS with driving anger $(\beta$ -0.07 versus $\beta-0.40$ ): in both cases, the highest values corresponded to the group of older drivers.

To check if any of these differences were significant, we compared the fit indices of the unconstrained model with the fit indices of a model in which all structural links were constrained to be equivalent. The differences in chi square were not significant $\left(\Delta \chi^{2}=19.6 ; \Delta d f=13 ; p>0.10\right)$. In addition, the differences in CFI $(\Delta \mathrm{CFI}=0.009)$ did not reach the generally accepted limit of 0.01 as a decision criterion either. Therefore, despite the differences in these and some other regression weights, from the indices obtained in this comparison, it can be said that the model of relationships between variables is equivalent for both age groups.

\section{Mediation Analyses}

To conclude, the AMOS-24 software calculated the indirect effects between constructs, and the significance of each effect was established by the bootstrapping confidence interval (Preacher \& Hayes, 2008). The results, for the model referred to the whole sample depicted in the Fig. 2, are summarized in Table 3.

According to Table 3, driving anger mediated the relationship from Agg-Host to the risky driving style; since the direct path between both variables was not significant, 


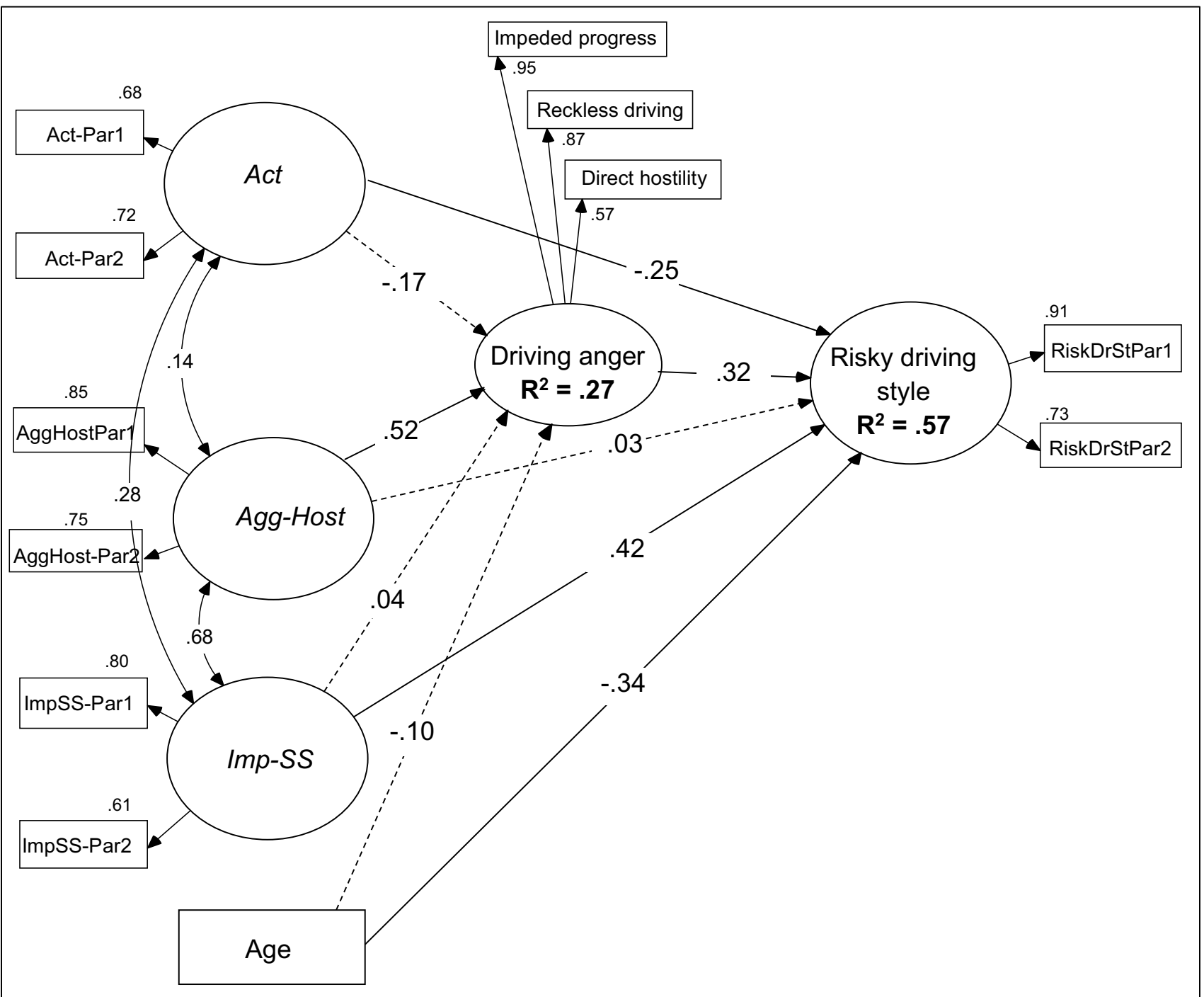

Fig. 3 Standardized values of the structural equation model of relations. Dashed lines represent no significant regression weights $(p>0.05)$

this relationship is considered to be full mediation. On the contrary, the role of driving anger mediating the influence of Act, Imp-SS and age on the risky driving style was not significant.

\section{Discussion}

Dangerous driving and road crime are a major road safety problem, but also a topic of social concern (Charlton, 2009). Regulatory and legislative changes in recent decades led to a tightening of sanctions, but new criminal offences were also introduced, as a consequence of this, the administrative sanctions were tightened, the penalty point system in driwing lecenses was introduced and infractions that were previously administratively sanctioned, became criminal offenses (Castillo-Manzano et al., 2015; Montag, 2014;
Rebollo-Sanz et al., 2021), which has led to a significant increase in the proceedings brought, both by prior diligence and urgent proceedings, representing one third of all convictions for any type of offence (Fiscalía General del Estado, 2019), with the consequent increase of people entering the prisons, as a result of the commission of a crime against road safety. In addition, this has caused a significant number of people who have never been convicted to enter prison before, for any kind of crime (Hilterman et al., 2012). It is very necessary to know the profile of these individuals, in order to prevent recidivism and to design rehabilitative strategies (Fiscalía General del Estado, 2017; Monras et al., 2011) Therefore, one of the main strengths of this work has to do with studying this issue in a population - people deprived of their liberty by the commission of crimes against road safety - in which very little is known about its clinical and sociodemographic characteristics, given the lack of studies 


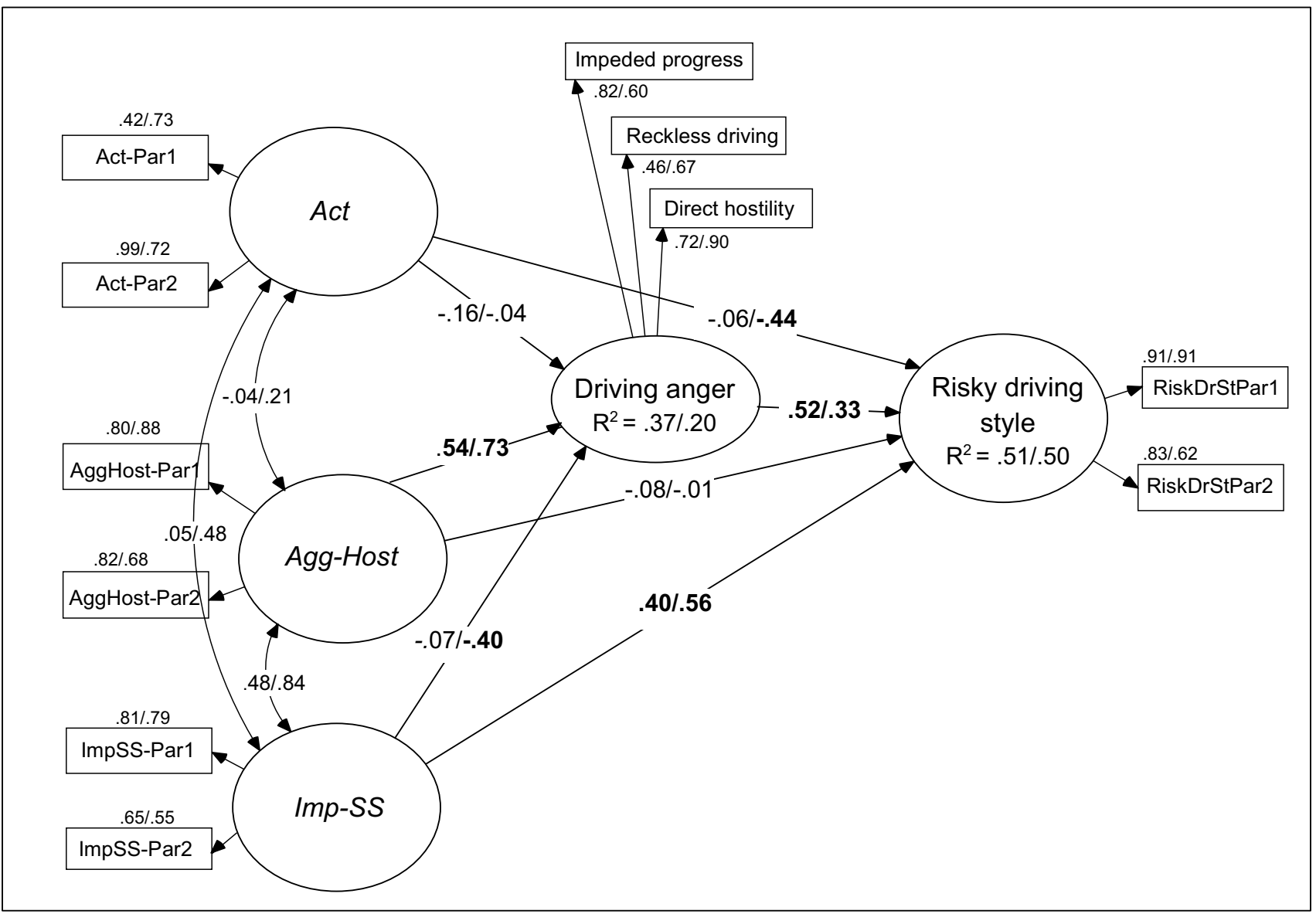

Fig. 4 Standardized paths for multi-group analysis ( $\leq 40$ years old $/ v s />40$ years old). Note: in bold, significant regression weights (p $<.05)$

Table 3 Direct, indirect, and total effects between variables

\begin{tabular}{llll}
\hline $\begin{array}{l}\text { Predictor } \rightarrow \\
\text { Criterion }\end{array}$ & Direct effect $(p)$ & $\begin{array}{l}\text { Indirect } \\
\text { effect }(\mathrm{p})\end{array}$ & $\begin{array}{l}\text { Total } \\
\text { effect }(p)\end{array}$ \\
\hline $\begin{array}{l}\text { Full mediation } \\
\quad \text { Agg-Host } \rightarrow\end{array}$ & $0.034(\mathrm{~ns})$ & 0.169 & 0.203 \\
$\quad \begin{array}{l}\text { Risky driving style } \\
\text { No mediation }\end{array}$ & & $(0.001)$ & $(0.001)$ \\
$\quad \begin{array}{ll}\text { Act } \rightarrow \\
\text { Risky driving style }\end{array}$ & $-0.259(0.003)$ & -0.057 & $-0.316(0.001)$ \\
$\quad$ & & $(\mathrm{ns})$ & \\
Impe-SS $\rightarrow$ & $0.424(0.001)$ & -0.014 & 0.410 \\
Risky driving style & & $(\mathrm{ns})$ & $(0.001)$ \\
$\quad \begin{array}{l}\text { Age } \rightarrow \\
\text { Risky driving style }\end{array}$ & $-0.347(0.001)$ & -0.034 & $-0.381(0.001)$ \\
& & $(\mathrm{ns})$ & \\
\hline
\end{tabular}

The probability associated with each standardized indirect effect was calculated through the two-sided bias-corrected confidence interval (CI) bootstrap test of AMOS-24, with a 95\% CI and 5000 samples. $(\mathrm{ns})=$ not significant $(p>0.05)$

in this regard (Faílde et al., 2018; Monras et al., 2011). It is, therefore, of great importance for the rehabilitation of this type of offenders to have data that allow us to design effective and individualized therapeutic strategies (Bartl et al., 2002; Woodall et al., 2004).

On the other hand, while it is true that in recent decades the number of studies that seek to know the relationship between personality characteristics and risky driving styles has increased, it is also true that most have been carried out from the theoretical model of the big five, mainly with the Revised NEO Personality Inventory (Costa \& McCrae, 1992), with relatively few doing so from Zuckerman's Alternative Five-Factor Model (Zuckerman, et al., 1993). This model aims to integrate various personality dimensions into macrofactors that have been associated with the two main problematic behaviours for road safety: risky and aggressive driving style (Gulliver \& Begg, 2007; Paleti et al., 2010).

Our results partially confirm and expand the findings of previous studies (Bogdan et al., 2016; Monteiro et al., 2018; Poó \& Ledesma, 2013; Zhang \& Chan, 2016) except that most have been made with samples, from community drivers, professionals, or university students and, to a lesser extent, with persons serving custodial sentences for the commission of crimes against road safety. 
Thus, the supra-trait Imp-SS, a personality dimension that characterizes individuals with "poor ability to plan and with a tendency to act impulsively without thinking about the consequences and actively seeking new experiences that involve excitement and risk" (Poó \& Ledesma, 2013), acted as a direct predictor with a positive sign of risky driving, confirming previous findings (Begg \& Angley, 2004; Poó \& Ledesma, 2013; Richer \& Bergeron, 2012).

For its part, the Agg-Host trait, which characterizes people with a predisposition to express verbal aggression, rudeness, in consideration towards others, antisocial behavior and desire for revenge and malice (Poó \& Ledesma, 2013), showed himself in our model as an indirect predictor, showing a strong positive relationship with anger in driving, which acted as a mediating variable of the risky driving style. This finding confirms the model, by placing anger in driving as a proximal factor, in line with the proposed in the model of Demir et al. (2016) and confirming the relationship between driving anger and the style of risky driving (Dingus et al., 2016; Richer \& Bergeron, 2012). On the other hand, the role of driving anger mediating the influence of Act, Imp$S S$ and age on risky driving style was not significant, which contradicts the model predictions.

As regards the Act trait defined as the need for general activity, difficulty for relaxing or doing nothing when possible and preference for hard work, energy-consumingand busylife (Poó \& Ledesma, 2013), has not been found in previous studies that relate to risky driving, or other risky behaviors such as drinking, smoking, drug use, sexual risky and gambling (Zuckerman \& Kuhlman, 2000). For their part, Poó et al. (2008) indicate that despite no studies that relate risk in driving with this trait, a positive correlation could be expected. However, our model yields an unexpected result by finding that the Act behaved as a direct, negative-signed predictor. However, this result is by no means inconsistent, as the Act personality trait has been positively related to non-problematic driving behaviours or adaptive/constructive forms of anger expression (Sârbescu, 2012; Sârbescu et al., 2012). Thus, it is recommended to pay more attention to the study of the relationship between the Act trait and the risky driving style, in future research.

On the other hand, in line with other studies, we have not found that the $N-A n x$ and $S y$ traits relate to the risky driving style (Zuckerman \& Kuhlman, 2000) or driving anger.

The model used in this study allowed us to explain a high percentage of the variance of the risky driving style variable, demonstrating the importance of how useful assessing global personality traits, and anger driving are in the prediction of risky driving styles.

Variables, all of them, which should be considered both in the evaluation and in the training of future drivers, as well as in the re-education of offenders who go through road awareness and re-education courses or in the rehabilitation of criminals punishable for road safety offences.

Sociodemographic characteristics, such as age or gender, should also be considered, since as it has been reported in different studies, young and male drivers accumulate many more infractions and convictions against road safety (Delhomme et al., 2012; Marengo et al., 2012).

While it is true that in Spain, as in many other countries, road education programmes are carried out, such as the TASEVAL - an educational road safety workshop, which aims for offenders to internalize civic values in the use of public roads and to raise awareness of the danger of alcohol and other toxic substances at the wheel-and PROSEVALPsychoeducational Intervention Programme in Road Safety, with specific therapeutic content-(Ministerio del Interior, 2016). The truth is that, in most cases, these are training strategies that are fundamentally based on the transmission of knowledge and have not reported scientific evidence. So, it is necessary, that prevention and treatment actions are done based on empirical evidence. In this sense, there is scientific evidence showing that certain therapeutic strategies (relaxation, behavioral and cognitive therapies) are useful in the treatment of drivers with high levels of anger (Deffenbacher, 2016). In addition, although not abundant, there is scientific evidence to support the effectiveness of programs to rehabilitate individuals convicted of driving under the influence (Miller et al., 2015). So empirically validated preventive and therapeutic strategies demonstrating usefulness in this field should be identified.

\section{Conclusions and Practical Implications}

By and large, our study partially confirms the predictions of the contextual model, anger in driving was placed in the proximal context, mediating the effect of the Aggr-Host personality trait, which was placed in the distal context. In addition, driving anger had an important mediating effect on the outcome variable Risky driving. These results are consistent with the model proposed by Demir et al. (2016). On the other hand, age and personality traits Act and Imp-SS were direct predictors, contradicting what is hypothesized by the model proposed by Demir et al. (2016) and indicated by other theoretical proposals, such as the Contextual Model of Sümer (2003). Finally, the Sy and N-Anx traits were not related to risky driving. In view of these results, we can conclude that the established hypotheses have only been partially validated.

The results of this study can be translated into practical measures that we can place at three levels:

Primary prevention, psychotechnical tests should include in their evaluation tools to identify driving styles, and per- 
sonal characteristics or personality traits that may pose a risk to driving, providing specific advice for future drivers based on their results, through brief interventions, with strategies that have shown clinical usefulness in other areas, such as brief counselling or minimal intervention (Harlow, 2006; Slama et al., 1995).

Secondary prevention, should be detected and treated early for road offenders through screening tools and evidence-based therapies. For example, in the case of road offenders with high levels of driving anger (Deffenbacher, 2016; Holman \& Popușoi, 2020; Lucidi et al., 2019) helping them in their regulation (Mirón-Juárez et al., 2020), with problems using alcohol or drugs (Miller et al., 2015), or with risky or aggressive driving styles. This requires reliable and brief measures to evaluate key variables and have empirically validated treatment strategies.

Tertiary prevention/rehabilitation, they would be aimed at multiple-offense offenders or to convicts who enter prison. These should be evaluated and treated through empirically supported treatments. Therefore, it is necessary to investigate which strategies and rehabilitation programs, for road criminals have empirical evidence. In addition, the different profiles of road criminals must be identified, investigating which therapeutic strategies are best suited for each criminal profile. This therefore implies knowing the characteristics of road safety offenders, so as to design and implement treatment strategies or rehabilitative measures that allow them to respond to their uniqueness (Woodall et al., 2004) and that have scientific evidence.

\section{Limitations of the Study and Future Lines of Research}

Although this study contributes to providing information on a group in which studies are scarce, and that their results may be useful for the design of preventive and/or rehabilitative strategies, it presents several limitations that should be taken into consideration. First, the measures were obtained primarily through questionnaire data, although it is true that there is evidence indicating that the response biasess of selfreports are not as important as presupposed. In this sense, some studies comparing measures of selfreports and traffic offences with official accident records indicate that they hardly differ (Boufous et al., 2010), and were also sparsely affected their results by the bias of social desyability (Lajunen and Summala, 2003; Taubman-Ben-Arib, 2006). In addition, this study has been conducted exclusively with males, this is because very few women currently serve time for road safety offences (Fiscalía General del Estado, 2019).

Future research should go into detail about the study of the psychosocial characteristics of people who enter prison for crimes against road safety, expanding the knowledge and study of the relationships of personality traits, anger in driving with aberrant driving styles (risky and aggressive), especially using the Zuckerman pentafactorial model of which we have hardly any data in this area. Likewise, it would be of interest to increase the knowledge on the relationship between personality traits and the expression of anger in driving (verbal, physical or on the behaviour of the driver) and on the ways of adaptively handling anger while driving (Karimi et al., 2021), an aspect that could have relevance in the design and implementation of rehabilitative measures for offending drivers or road offenders, who have high levels of driving anger.

Acknowledgements The authors thank the inmates and staff at Galician prisons for their generous cooperation and participation. Funding for open access charge: Universidade de Vigo/CISUG".

Authors' Contributions (optional: please review the submission guidelines from the journal whether statements are mandatory) Faílde, J.M.: Conceptualization, Methodology, Formal analysis, Writing-original draft. Supervision. Rodriguez, Y.: Conceptualization, Methodology Writing_original draft. González, A.: Formal analysis, Writing - review and editing. García, M.A.: Conceptualization, Methodology, Writing- original draft.

Funding (information that explains whether and by whom the research was supported) Open Access funding provided thanks to the CRUECSIC agreement with Springer Nature. The present study was partially financed by the Provincial Council of Ourense and by the University of Vigo, through the INOU projects Ref. 0612 Principal investigator José María Faílde Garrido.

Data Availability (data transparency) The data are publicly available for download from the Inter-university Consortium for Political and Social Research (ICPSR): https://www.openicpsr.org/openicpsr/works pace?goToPath=/openicpsr/129361\&goToLevel=project

Code Availability (software application or custom code) 'Not applicable' for that section.

\section{Declarations}

Conflicts of Interest/Competing interests (include appropriate disclosures) The authors declare that they have no conflict of interest.

Open Access This article is licensed under a Creative Commons Attribution 4.0 International License, which permits use, sharing, adaptation, distribution and reproduction in any medium or format, as long as you give appropriate credit to the original author(s) and the source, provide a link to the Creative Commons licence, and indicate if changes were made. The images or other third party material in this article are included in the article's Creative Commons licence, unless indicated otherwise in a credit line to the material. If material is not included in the article's Creative Commons licence and your intended use is not permitted by statutory regulation or exceeds the permitted use, you will need to obtain permission directly from the copyright holder. To view a copy of this licence, visit http://creativecommons.org/licenses/by/4.0/. 


\section{References}

Aluja, A., Rossier, J., Garcia, L., Angleitner, A., Kuhlman, M., \& Zuckerman, M. (2006). A cross-cultural shortened form of the ZKPQ (ZKPQ-50-CC) adapted to English, French, German, and Spanish languages. Personality and Individual Differences, 41, 619-628. https://doi.org/10.1016/j.paid.2006.03.001

Baron, R. M., \& Kenny, D. A. (1986). The moderator-mediator variable distinction in social psychological research: Conceptual, strategic and statistical considerations. Journal of Personality and Social Psychology, 51, 1173-1182. https://doi.org/10.1037//0022-3514. 51.6.1173

Bartl, G., Assailly, J. P., Chatenet, F., Hatakka, M., Keskinen, E., \& Willmes-Lenz, G. (2002). EU-project Andrea: Analysis of Driver Rehabilitation Programmes. Vienna: KuratoriumFur Verkehrssicherheit. Retrieved November 20, 2021, from: https://ec.europa. eu/transport/road_safety/sites/roadsafety/files/pdf/projects/ andrea_final_report.pdf.

Begg, D. J., \& Angley, J. D. (2004). Identifying predictors of persistent non-alcohol or drug related risky driving behaviours among a cohort of young adults. Accident Analysis and Prevention, 36, 1067-1071. https://doi.org/10.1016/j.aap.2004.03.001

Berdoulat, E., Vavassori, D., \& Sastre, M. T. M. (2013). Driving anger, emotional and instrumental aggressiveness, and impulsiveness in the prediction of aggressive and transgressive driving. Accident Analysis and Prevention, 50, 758-767. https://doi.org/10.1016/j. aap.2012.06.029

Bogdan, S., Mairean, C., \& Havarneanu, C. (2016). A meta-analysis of the association between anger and aggressive driving. Transportation Research Part F: Traffic Psychology and Behaviour., 42(2), 350-364. https://doi.org/10.1016/j.trf.2016.05.009

Boufous, S., Ivers, R., Senserrick, T., Stevenson, M., Norton, R., \& Williamson, A. (2010). Accuracy of self-report of on-road crashes and traffic offences in a cohort of young drivers: The DRIVE study. Injury Prevention, 16, 275-277. https://doi.org/10.1136/ ip.2009.024877

Burtăverde, V., Chraif, M., Aniţei, M., \& Mihăilă, T. (2016). The incremental validity of the dark triad in predicting driving aggression. Accident Analysis and Prevention, 96, 1-11. https://doi.org/10. 1016/j.aap.2016.07.0

Byrne, B. (2016). Structural equation modeling with AMOS. Basic concepts, applications, and programming. Routledge.

Calafat, A., \& Duch, M. A. (2009). Preventive interventions in nightlife: A review. Adicciones, 21(4), 387-414. https://doi.org/10. 20882/adicciones.226.

Caprara, G. V., Barbaranelli, C., Borgogni, L., \& Perugini, M. (1993). The big five questionnaire: A new questionnaire for the measurement of the five factor model. Personality and Individual Differences, 15, 281-288. https://doi.org/10.1016/0191-8869(93) 90218-R

Castillo-Manzano, J. I., Castro-Nuño, M., \& Fageda, X. (2015). Can cars and trucks coexist peacefully on highways? Analyzing the effectiveness of road safety policies in Europe. Accident Analysis and Prevention, 77, 120-126. https://doi.org/10.1016/j.aap.2015. 01.010

Charlton, S. G. (2009). Driving while conversing: Cell phones that distract and passengers who react. Accident Analysis and Prevention, 41(1), 160-173. https://doi.org/10.1016/j.aap.2008.10.006

Costa, P. T., \& McCrae, R. R. (1992). Revised NEO Personality Inventory (NEO-PI-R) and NEO Five-Factor Inventory (NEO-FFI) Professional Manual. Psychological Assessment Resources.

Deffenbacher, J. L. (2016). A review of interventions for the reduction of driving anger. Transportation Research Part F: Traffic
Psychology and Behaviour, 42(2), 411-421. https://doi.org/10. 1016/j.trf.2015.10.024

Deffenbacher, J. L., Oetting, E. R., \& Lynch, R. S. (1994). Development of a driving anger scale. Psychological Reports, 74, 83-91. https://doi.org/10.2466/pr0.1994.74.1.83

Deffenbacher, J. L., Stephens, A. N., \& Sullman, M. J. M. (2016). Driving anger as a psychological construct: Twenty years of research using the driving anger scale. Transportation Research Part F: Traffic Psychology and Behaviour, 42(2), 236-247. https://doi. org/10.1016/j.trf.2015.10.021

Delhomme, P., Chaurand, N., \& Paran, F. (2012). Personality predictors of speeding in young drivers: Anger vs. sensation seeking. Transportation Research Part F: Traffic Psychology and Behaviour, 15, 654-666. https://doi.org/10.1016/j.trf.2012.06.006

Demir, B. R., Demir, S., \& Özkan, T. (2016). A contextual model of driving anger: A meta-analysis. Transportation Research Part F: Traffic Psychology and Behaviour, 42, 332-349. https://doi.org/ 10.1016/j.trf.2016.09.020

Dingus, T. A., Guo, F., Lee, S., Antin, J. F., Perez, M., Buchanan-King, M., \& Hankey, J. (2016). Driver crash risk factors and prevalence evaluation using naturalistic driving data. Proceedings of the National Academy of Sciences, 113(10), 2636-2641. https:// doi.org/10.1073/pnas.1513271113

Dula, C. S., \& Geller, E. S. (2003). Risky, aggressive, or emotional driving: Addressing theneed for consistent communication in research. Journal of Safety Research, 34, 559-566. https://doi. org/10.1016/j.jsr.2003.03.004

Edwards, B. D., Warren, C. R., Tubré, T. C., Zyphur, M. J., \& HoffnerPrillaman, R. (2013). The validity of narcissism and driving anger in predicting aggressive driving in a sample of young drivers. Human Performance, 26(3), 191-210. https://doi.org/10.1080/ 08959285.2013.795961

Elander, J., West, R., \& French, D. (1993). Behavioral correlates of individual differences in road-traffic crash risk: An examination of methods and findings. Psychological Bulletin, 113, 279-294. https://doi.org/10.1037/0033-2909.113.2.279

Faílde, J. M., García, M. A., Carrera, M. V., Rodríguez, Y., Lameiras, M., \& Ruiz, L. (2018). A qualitative approach to the study of the characteristics of individuals convicted of road traffic offences. International Journal of Law and Psychiatry, 59, 10-19. https:// doi.org/10.1016/j.ijlp.2018.05.003

Feng, Z., Yang, M., Ma, C., Jiang, K., Lei, Y., Huang, W., . . ., Zhou, M. (2017). Driving anger and its relationships with type A behavior patterns and trait anger: Differences between professional and non-professional drivers. PLoS One, 12(12), 17. https://doi.org/ 10.1371/journal.pone.0189793.

Fiscalía General del Estado (2017). Memoria elevada al Gobierno de S.M. presentada al inicio del año judicial. Madrid: Centro de Estudios Jurídicos del Ministerio de Justicia. Retrieved November 20, 2021, from: https://www.fiscal.es/memorias/memoria2017/ FISCALIA_SITE/recursos/pdf/MEMFIS17.pdf.

Fiscalía General del Estado (2019). Memoria elevada al Gobierno de S.M. presentada al inicio del año judicial. Madrid: Centro de Estudios Jurídicos del Ministerio de Justicia. Retrieved November 20, 2021, from: https://d3cra5ec8gdi8w.cloudfront.net/uploads/ documentos/2019/09/10/_memoria2019_76609dd4.pdf.

Gulliver, P., \& Begg, D. (2007). Personality factors as predictors of persistent risky driving behavior and crash involvement among young adults. Injury Prevention, 13, 376-381. https://doi.org/10. 1136/ip.2007.015925

Harlow, K. C. (2006). The effectiveness of a problem resolution and brief counseling EAP intervention. Journal of Workplace Behavioral Health, 22(1), 1-12. https://doi.org/10.1300/J490v22n01_01 
Harris, P., \& Houston, J. (2010). Recklessness in context. Environment and Behavior, 42, 44-60. https://doi.org/10.1177/00139 165083252

Harris, P., Houston, J., Vazquez, J., Smither, J., Harms, A., Dahlke, J., \& Sachau, D. (2014). The Prosocial and Aggressive Driving Inventory (PADI): A self-report measure of safe and unsafe driving behaviors. Accident Analysis and Prevention, 72, 1-8. https:// doi.org/10.1016/j.aap.2014.05.023

Hasaninasab, S., Jalili, S., \& Mirani, K. (2021). Evaluation effects of personality on the young people traffic offense and accident. Iranian Journal of Science and Technology Transactions of Civil Engineering, 45, 491-503. https://doi.org/10.1007/ s40996-020-00399-5

Hatfield, J., \& Fernandes, R. (2009). The role of risk-propensity in the risky driving of younger drivers. Accident Analysis and Preventión, 41(1), 25-35. https://doi.org/10.1016/j.aap.2008.08.023

Herrero-Fernández, D. (2011). Psychometric adaptation of the driving anger expression inventory in a spanish sample: Differences by age and gender. Transportation Research Part F: Traffic Psychology and Behaviour, 14(4), 324-329. https://doi.org/10.1016/j.trf. 2011.03.001

Hilterman, E.D., Mancho, R., Trasovares, M.V., Baldris, G., Muñoz, Y. (2012). Programas de tratamiento y características de los internos penitenciarios ingresados por delitos de tráfico en Cataluña [Treatment programs and characteristics of prison inmates admitted for traffic offenses in Catalonia]. Centre d'Estudis Jurídics i Formació Especialitzada. Retrieved November 20, 2021, from: https://www.recercat.cat/bitstream/handle/2072/200844/ programas_tratamiento_cast.pdf?sequence $=1$.

Holman, A. C., \& Popuşoi, S. A. (2020). How you deal with your emotions is how you drive. Emotion regulation strategies, traffic offenses, and the mediating role of driving styles. Sustainability, 12(12), 4929. https://doi.org/10.3390/su12124929

Javid, M. A., \& Al-Hashimi, A. R. (2020). Significance of attitudes, passion and cultural factors in driver's speeding behavior in Oman: Application of theory of planned behavior. International Journal of Injury Control and Safety Promotion, 27, 172-180. https://doi.org/10.1080/17457300.2019.1695632

Javid, M. A., Ali, N., Shah, S. A. H., \& Abdullah, M. (2021). Structural equation modeling of drivers' speeding behavior in Lahore: Importance of attitudes, personality traits, behavioral control, and traffic awareness. Iranian Journal of Science and Technology, Transactions of Civil Engineering. https://doi.org/10.1007/ s40996-021-00672-1

Jeon, M., Walker, B. N., \& Yim, J. B. (2014). Effects of specific emotions on subjective judgment, driving performance, and perceived workload. Transportation Research Part F: Traffic Psychology and Behaviour, 24, 197-209. https://doi.org/10.1016/J.TRF.2014. 04.003

Jovanović, D., Lipovac, K., Stanojević, P., \& Stanojević, D. (2011). The effects of personality traits on driving-related anger and aggressive behaviour in traffic among Serbian drivers. Transportation Research Part F: Traffic Psychology and Behaviour, 14(1), 43-53. https://doi.org/10.1016/j.trf.2010.09.005

Karimi, S., Aghabayk, K., Abrari Vajari, M., \& Stephens, A. (2021). Aggressive driving: Self-reported anger expression and its relationship with driver personality. International Journal of Transportation Engineering, 8(3), 299-316. https://doi.org/10.22119/ IJTE.2021.254078.1541

Kovácsová, N., Rosková, E., \& Lajunen, T. (2014). Forgivingness, anger, and hostility inaggressive driving. Accident Analysis and Preventión, 62, 303-308. https://doi.org/10.1016/j.aap.2013.10. 017

Lajunen, T. (1997). Personality Factors, Driving Style, and Traffic Safety (doctoral Thesis). University of Helsinki.
Lajunen, T., \& Parker, D. (2001). Are aggressive people aggressive drivers? A study of the relationship between self-reported general aggressiveness, driver anger and aggressive driving. Accident Analysis and Prevention, 33(2), 243-255. https://doi.org/10.1016/ s0001-4575(00)00039-7

Lajunen, T., \& Summala, H. (2003). Can we trust self-reports of driving? Effects of impression management on driver behaviour questionnaire responses. Transportation Research Part F: Traffic Psychology and Behaviour, 6(2), 97-107. https://doi.org/10.1016/ S1369-8478(03)00008-1

Lawton, R., Parker, Manstead, A. S. R., \& Stradling, S. G. (1997). The role of affect in predicting social behaviours: the case of road traffic violations. Journal of Applied Social Psychology, 27(14), 1258-1276. https://doi.org/10.1111/j.1559-1816.1997.tb01805.x

Long, S., \& Ruosong, C. (2019). Reliability and validity of the multidimensional driving style inventory in chinese drivers. Traffic Injury Prevention, 20(2), 1-6. https://doi.org/10.1080/15389588. 2018.1542140

Lucidi, F., Girelli, L., Chirico, A., Alivernini, F., Cozzolino, M., Violani, C., \& Mallia, L. (2019). Personality traits and attitudes toward traffic safety predict risky behavior across young, adult, and older drivers. Frontiers in Psychology, 10, 536. https://doi. org/10.3389/fpsyg.2019.00536

Marengo, D., Settanni, M., \& Vidotto, G. (2012). Drivers' subtypes in a sample of Italian adolescents: Relationship between personality measures and driving behavior. Transportation Research Part F: Traffic Psychology and Behaviour, 15, 480-490. https://doi.org/ 10.1016/j.trf.2012.04.001

McEvoy, S. P., Stevenson, M. R., \& Woodward, M. (2007). The prevalence of and factors associated with, serious crashes involving a distracting activity. Accident Analysis and Prevention, 39(3), 475-482. https://doi.org/10.1016/j.aap.2006.09.005

McKenna, F. P. (1983). Accident proneness: A conceptual analysis. Accident Analysis and Prevention, 15, 65-71. https://doi.org/10. 1016/0001-4575(83)90008-8

McNally, B., \& Bradley, G. L. (2014). Re-conceptualising the reckless driving behaviour of young drivers. Accident Analysis and Prevention, 70, 245-257. https://doi.org/10.1016/j.aap.2014.04.014

Miller, P. G., Curtis, A., Sønderlund, A., Day, A., \& Droste, N. (2015). Effectiveness of interventions for convicted DUI offenders in reducing recidivism: A systematic review of the peer-reviewed scientific literatura. The American Journal of Drug and Alcohol Abuse, 41(1), 16-29. https://doi.org/10.3109/00952990.2014. 966199

Ministerio del Interior (2016). PROSEVAL - Programa de intervención psicoeducativa en seguridad vial. Manual del profesional. Ministerio del Interior, Secretaría General Técnica. Retrieved November 20, 2021, from: http://www.interior.gob.es/documents/642317/ 1201664/PROSEVAL_Manual_para_el_participante_12616 0449_web.pdf/105a7d90-7740-45fa-9c91-fc3a411d4490.

Mirón-Juárez, C. A., García-Hernández, C., Ochoa-Ávila, E., \& DíazGrijalva, G. R. (2020). Approaching to a structural model of impulsivity and driving anger as predictors of risk behaviors in young drivers. Transportation Research Part F: Traffic Psychology and Behaviour, 72, 71-80. https://doi.org/10.1016/j.trf.2020. 05.006

Mohan, D., Tiwari, G., Meleckidzedeck, K., \& Fredrick, M.N. (2006). Road traffic injury prevention training manual. World Health Organization and Indian Institute of Technlogy Delhi. Retrieved November 20, 2021, from: https://apps.who.int/iris/bitstream/handle/10665/43271/9241546751_eng.pdf;jsessionid=41269EC5E0 994D975E1F205052AA5431? sequence $=1$.

Monras, M., Aparicio, A., López, J. A., \& Pons, I. (2011). Causas de los ingresos en prisión por delitos contra la seguridad vial: ¿enfermedad o irresponsabilidad? [Causes of revenues in prison for crimes against road safety: Disease or irresponsibility?]. 
Medicina Clínica (barcelona), 137(6), 279-280. https://doi.org/ 10.1016/j.medcli.2010.07.012

Montag, J. (2014). A radical change in traffic law: Effects on fatalities in the Czech Republic. Journal of Public Health, 36(4), 539-545. https://doi.org/10.1093/pubmed/fdu005

Monteiro, R. P., Coelho, G. L. H., Hanel, P. H. P., Pimentel, C. E., \& Gouveia, V. V. (2018). Personality, dangerous driving, and involvement in accidents: Testing a contextual mediated model. Transportation Research Part F - TrafficPsychology and Behaviour, 58, 106-114. https://doi.org/10.1016/j.trf.2018.06.009

Nesbit, S. M., \& Conger, J. C. (2011). Evaluation of cognitive responses to anger-provoking driving situations using the articulated thoughts during simulated situations procedure. Transportation Research Part F: Traffic Psychology and Behaviour, 14(1), 54-65. https://doi.org/10.1016/j.trf.2010.09.006

Owens, J. M., McLaughling, S. B., \& Sudweeks, J. (2011). Driver performance while text messaging using handheld and in-vehicle systems. Accident Analysis and Prevention, 43(3), 939-947. https:// doi.org/10.1016/j.aap.2010.11.019

Padilla, J. L., Castro, C., Doncela, P., \& Taubman Ben-Arib, O. (2020). Adaptation of the multidimensional driving styles inventory for Spanish drivers: Convergent and predictive validity evidence for detecting safe and unsafe driving styles. Accident Analysis and Prevention, 136, 105413. https://doi.org/10.1016/j.aap.2019. 105413

Paleti, R., Eluru, N., \& Bhat, C. R. (2010). Examining the influence ofaggressive driving behavior on driver injury severity in trafficcrashes. Accident Analysis and Prevention, 42(6), 1839-1854. https://doi.org/10.1016/j.aap.2010.05.005

Paulhus, D., \& Williams, K. (2002). The dark triad of personality: Narcissism, machiavellianism, and psychopathy. Journal of Research in Personality, 36(6), 556-563. https://doi.org/10.1016/S00926566(02)00505-6

Poó, F, Ledesma, R. \& Montes, S. (2008). Rasgos de personalidad y agresión en conductores [Personality traits and aggression in drivers]. Avaliação Psicologica, 7(3), 269-280. Retrieved November 20, 2021, https://www.redalyc.org/pdf/3350/335027185002.pdf.

Poó, F., Taubman-Ben-Ari, O., Ledesma, R., \& Díaz-Lázaro, C. (2013). Reliability and validity of a spanish-language version of the multidimensional driving style inventory. Transportation Research Part F: Traffic Psychology and Behaviour, 17, 75-87. https://doi. org/10.1016/j.trf.2012.10.003

Poó, F. M., \& Ledesma, R. D. (2013). A study on the relationship between prsonality and driving styles. Traffic Injury Preventio, 14, 346-352. https://doi.org/10.1080/15389588.2012.717729

Preacher, K., \& Hayes, A. (2008). Asymptotic and resampling strategies for assessing and comparing indirect effects in multiple mediator models. Behavior Research Methods, 40(3), 879-891. https://doi.org/10.3758/BRM.40.3.879

Precht, L., Keinath, A., \& Krems, J. F. (2017). Effects of driving anger on driver behavior-results fromnaturalistic driving dataq. Transportation Research Part F, 45, 75-92. https://doi.org/10.1016/j. trf.2016.10.019

Reason, J. T., Manstead, A., Stradling, S., Baxter, J. S., \& Campbell, K. (1990). Errors and violations on the roads: A real distinction? Ergonomics, 33, 1315-1332. https://doi.org/10.1080/0014013900 8925335

Rebollo-Sanz, Y., Rodríguez-López, J., \& Rodríguez-Planas, N. (2021). Penalty-point system, deterrence and road safety: A quasi-experimental analysis. Journal of Economic Behavior and Organization, 190, 408-433. https://doi.org/10.1016/j.jebo.2021.08.007

Richer, I., \& Bergeron, J. (2012). Differentiating risky and aggressive driving: Further support of the internal validity of the Dula Dangerous Driving Index. Accid Analysis and Prevention, 45, 620-627. https://doi.org/10.1016/j.aap.2011.09.014
Sánchez, F., \& Quiroga, M. A. (2005). Prevention of traffic accidents: The assessment of perceptualmotor alterations before obtaining a driving license. A longitudinal study of the first years of driving. Brain Injury, 19(3), 189-196. https://doi.org/10.1080/02699 050400017189

Sârbescu, P. (2012). Aggressive driving in Romania: Psychometric properties of the driving anger expression inventory. Transportation Research Part F, 15, 556-564. https://doi.org/10.1016/j.trf. 2012.05.009

Sârbescu, P. (2016). Driving anger scale: How reliable are subscale scores? A bifactor model analysis. Transportation Research Part F: Traffic Psychology and Behaviour, 42, 248-254. https://doi.org/ 10.1016/j.trf.2012.05.009

Sârbescu, P., Costea, I., \& Rusu, S. (2012). Using the alternative Five Factor Personality Model to explain driving anger expression. Procedia-Social and Behavioral Sciences, 33, 273-277. https:// doi.org/10.1016/j.sbspro.2012.01.126

Shaw, I., \& Sichel, H. (1971). Accident proneness. Pergamon Press.

Simons-Morton, B., Lerner, N., \& Singer, J. (2005). The observed effects of teenage passengers on the risky driving behavior of teenage drivers. Accident Analysis and Prevention, 37(6), 973982. https://doi.org/10.1016/j.aap.2005.04.014

Singh, S. (2015). Critical reasons for crashes investigated in the national motor vehicle crash causation survey (Traffic Safety Facts. Crash_Stats. Report No. DOTHS 812 115). National Highway Traffic Safety Administration. Retrieved November 20, 2021, from: https://crashstats.nhtsa.dot.gov/Api/Public/ViewP ublication/812115.

Slama, K., Karsenty, S., \& Hirsh, A. (1995). Effectiveness of minimal intervention by general practitioners with their smoking patients: a randomised, controlled trial in France. Tabacco Control, 4, 162 169. Retrieved November 20, 2021, from: https://www.jstor.org/ stable/20747379.

Stephens, A. N., \& Sullman, M. J. M. (2015). Trait predictors of aggression and crash-related behaviors across drivers from the United Kingdom and the Irish Republic. Risk Analysis, 35(9), 1731-1745. https://doi.org/10.1111/risa.12379

Sullman, M. J. M., Gras, M. E., Cunill, M., Planes, M., \& Font-Mayolas, S. (2007). Driving anger in Spain. Personality and Individual Differences, 42, 701-713. https://doi.org/10.1016/j.paid.2006.08. 014

Sullman, M. J. M., Stephens, A. N., \& Yong, M. (2015). Anger, aggression and road ragebehaviour in Malaysian drivers. Transportation Research Part F: Traffic Psychology and Behaviour, 29, 70-82. https://doi.org/10.1016/j.trf.2015.01.006

Sümer, N. (2003). Personality and behavioral predictors of traffic accidents: Testing a contextual mediated model. Accident Analysis and Prevention, 35(6), 949-996. https://doi.org/10.1016/S00014575(02)00103-3

Taubman-Ben-Arib, O. (2006). Couple similarity for driving style. Transportation Research Part F-Traffic Psychology and Behaviour, 9(3), 185-193. https://doi.org/10.1016/j.trf.2005.11.001

Taubman-Ben-Arib, O., \& Skvirsky, V. (2016). The multidimensional driving style inventory a decade later: Review of the literature and re-evaluation of the scale. Accident Analysis \& Prevention, 93, 179-188. https://doi.org/10.1016/j.aap.2016.04.038

Taubman-Ben-Arib, O., \& Yehiel, D. (2012). Driving styles and their associations with personality and motivation. Accident Analysis and Prevention, 45, 416-422. https://doi.org/10.1016/j.aap.2011. 08.007

Ulleberg, P., \& Rundmo, T. (2003). Personality, attitudes and risk perception as predictors of risky driving behaviour among young drivers. Safety Science, 41(5), 427-443. https://doi.org/10.1016/ S0925-7535(01)00077-7 
Vlahogianni, E. I., Yannis, G., \& Golias, J. C. (2012). Overview of critical risk factors in Power-Two-Wheeler safety. Accident Analysis and Prevention, 49, 12-22. https://doi.org/10.1016/j.aap.2012. 04.009

Wang, Y., Qu, W., Ge, Y., Sun, X., \& Zhang, K. (2018). Effect of personality traits on driving style: Psychometric adaption of the multidimensional driving style inventory in a Chinese simple. PLoS ONE, 13(9), e0202126. https://doi.org/10.1371/journal. pone. 0202126

Woodall, W. G., Kunitz, S. J., Zhao, H., Wheeler, D. R., Westerberg, V., \& Davis, J. (2004). The prevention paradox, traffic safety, and driving-while-intoxicated treatment. American Journal of Preventive Medicine, 27(2), 106-111. https://doi.org/10.1016/j.amepre. 2004.04.012

Yang, J., Du, F., Qu, W., Gong, Z., \& Sun, X. (2013). Effects of personality on risky driving behavior and accident involvement for Chinese drivers. Traffic Injury Prevention, 14(6), 565-571. https:// doi.org/10.1080/15389588.2012.748903

Zhang, T., \& Chan, A. H. S. (2016). The association between driving anger and driving outcomes: A meta-analysis of evidence from the past twenty years. Accident Analysis and Prevention, 90, 50-62. https://doi.org/10.1016/j.aap.2016.02.009

Zhang, W., \& Qu, X. (2018). Driving anger and its relationshipwith aggressive driving among Chinese drivers. Transportation Research Part F: Traffic Psychology and Behaviour, 56, 496-507. https://doi.org/10.1016/j.trf.2018.05.011

Zuckerman, M., \& Kuhlman, D. M. (2000). Personality and risk-taking: Common biosocial factors. Journal of Personality, 68(6), 9991029. https://doi.org/10.1111/1467-6494.00124

Zuckerman, M., Kuhlman, M., Joireman, J., Teta, P., \& Kraft, M. (1993). A comparison of three structural models for personality: The big three, the big five, and the alternative five. Journal of Personality and Social Psychology, 65, 757-768. https://doi.org/ 10.1037/0022-3514.65.4.757

Publisher's Note Springer Nature remains neutral with regard to jurisdictional claims in published maps and institutional affiliations. 